\title{
A cross sectional study to assess perceived stress and stressors associated with it among undergraduate medical students in a private medical college of Uttar Pradesh, India
}

\author{
Varsha Chaudhary ${ }^{1}$, Deepak Upadhyay ${ }^{2}$, Shailendra Pratap $\operatorname{Singh}^{3}$, Arun Singh $^{2}$, Hari \\ Shankar Joshi ${ }^{2}$, Rashmi Katyal ${ }^{2}$
}

\begin{abstract}
${ }^{1}$ Department of Community Medicine, NSB subharti medical college, Meerut, Uttar Pradesh, India
${ }^{2}$ Department of Community Medicine, Rohilkhand Medical College and Hospital, Bareilly, Uttar Pradesh, India

${ }^{3}$ Department of Community Medicine, Government Medical College, Jalaun, Uttar Pradesh, India
\end{abstract}

Received: 06 May 2016

Accepted: 02 June 2016

\section{*Correspondence:}

Dr. Deepak Upadhyay,

E-mail: dr.deepakupadhyay@gmail.com

Copyright: ( ) the author(s), publisher and licensee Medip Academy. This is an open-access article distributed under the terms of the Creative Commons Attribution Non-Commercial License, which permits unrestricted non-commercial use, distribution, and reproduction in any medium, provided the original work is properly cited.

\section{ABSTRACT}

Background: Stress is a state of an individual that results from the interaction of the individual with the environment which is perceived as threatening or threat to the well-being. Medical students are expected to learn and master a huge amount of knowledge, attitudes and skills for which they have to work hard which in turn put them under a lot of stress. The present study was conducted with the objectives to assess and quantify the perceived stress, stressors and their severity and to assess the stressors associated with stress.

Methods: The present cross sectional study was under taken at Rohilkhand Medical College and Hospital, Bareilly, India. The study was conducted during October - November 2014. All students pursuing under-graduation in Allopathy Medicine (MBBS) were invited to participate in this study. Perceived stress was measured using the perceived stress scale (PSS-10). The students were asked to indicate if any of the 29 stressors had been affecting them. Binary logistic regression analysis was carried out to access the stressors significantly influencing the stress.

Results: $48.0 \%$ of the students were found to be stressed. Most frequently occurring academic sources of stress, psychosocial, and health related stressors reported by students as often/always were performance in examination (40.3\%), lack of entertainment in the institution (48.5\%) and quality of food in mess (50.7\%). Feeling of adoption of wrong carrier field, frequency of examination and lack of time for recreation, lack of entertainment in the institution and sleep disorder were found to be significantly associated with stress.

Conclusions: Medical education renders significant amount of stress to the students. There is need for measures to reduce such stress and future research.

Keywords: Academic stressors, Psychosocial stressors, PSS-10

\section{INTRODUCTION}

Stress is a state of an individual that result from the interaction of the individual with the environment which is perceived as threatening or threat to the well-being. It is an external constraint which directly upsets the individual both mentally and physically. Individual in a stressful situation is influenced by his or her mental ability to carry out on-going tasks. ${ }^{1,2}$ It is mentioned that tertiary education is highly stressful to students. ${ }^{3}$ Medical education is even more stressful as evidenced by high prevalence of stress among medical students, compared 
to other profession. Previous studies have shown fairly high levels of distress, such as symptoms of depression and even suicide thoughts among medical undergraduates. ${ }^{4-7}$ Medical students exposed to work overload in such a competitive environment with constant pressure of examination and assessment brings various changes in their daily habits such as lack of sleep, irregular diet, and substance abuse in the form of excessive consumption of alcohol and smoking in order to cope with the academic burden and stress. ${ }^{8-10}$ The students also face social, emotional and physical and family problems which may affect their learning ability and academic performance. ${ }^{11}$ Excessive stress may result in mental and physical problems and may diminish a student's sense of worth and might affect his/her academic achievement. ${ }^{12,13}$ Failing to cope with the stressors during the transition causes deterioration of academic and professional performances and increases the psychological distress. ${ }^{14}$ Perceived medical stress has also been linked to current mental distress and to forthcoming health problems. ${ }^{15}$ Earlier studies have classified stressors in to three main categories: academic stressors, psychosocial stressors and health related stressors Studies from developing countries like Thailand, India, Malaysia and even Pakistan have reported stress among medical students and have also underscored the role of academics as a potential stressor. ${ }^{16-20}$ But these studies either did not use the perceived stress scale or did not study the correlation between stress and academic performance. Studies have reported that academic constraints and also factors like age, gender, ethnicity and marital status may also influence students' severity of stress and hence academic performance. $^{21,22}$ At Rohilkhand Medical College and Hospital, Bareilly, India, there are students from different part of the state and from other states also. These students come from diverse cultural, socioeconomic and educational backgrounds. These students are exposed to a new learning environment, making new social circles and also adapting to new and different environment during their training at this college. Lack of studies on stress among medical students in this region warranted this study. The present study was conducted with the objective to assess and quantify the perceived stress, stressors and their severity and to assess the stressors associated with stress.

\section{METHODS}

\section{Setting and participants}

The present study was under taken at Rohilkhand Medical College and Hospital, Bareilly, India. Each year $\mathrm{RMCH}$ admits a batch of 100 students for the MBBS course. At a point of time there were five batches of students. At the end of each academic year the students sit for their professional examination, held by the MJPR University (Mahatama Jyotiba Phule Rohilkhand University) to qualify for the next academic year. The students of all the five year (2010, 2011, 2012, 2013 and
2014) were invited to participate in this study. The college campus is residential and it is obligatory to reside in the student hostel for all students.

\section{Study design}

A cross sectional survey was conducted using a selfadministered questionnaire. Prior approval from the institutional ethical committee was obtained. The study was conducted during October - November 2014. This time of the study was decided as it is the middle of the academic year for $2^{\text {nd }}, 3^{\text {rd }}, 4^{\text {th }}$ and $5^{\text {th }}$ year medical students so they were not burdened for any particular stressor like examination performance, attendance, lack of recreational activities. For the first year students that admitted in the institution in July, this time of the study gave them sufficient time to adjust in new environment and also prevent from other stressor like loneliness, accommodation away from home etc. Ragging is banned in the institution and fresher party is given to newly admitted batch usually after 1 month. Therefore Oct- Nov was considered as the best time to quantify stress without being skewed towards any particular stressors i.e. ragging, academic stressor, psychological and health related stressor.

Each batch was instructed prior about the purpose and objective of the study and asked to gather at a predefined place on predefined time and day. Day, time and place were decided as there would be no disturbance in academic and out of academic activities after discussing with students and concern authorities. Students were assured about confidentiality of the responses.

All the students present on predefined time and place were instructed to fill the questionnaire. Before filling the questionnaire, each question was explained to students so that they could understand the questionnaire completely and could answer properly. Single observer demonstrated the questionnaire to all batches. Completion of questionnaire was ensured at the time of collection.

\section{Definition of variables}

Perceived stress - perceived stress was measured using the perceived stress scale (PSS-10) which comprised of 10 questions with responses varying from 0 to 4 for each item and ranging from never, almost never, sometimes, fairly often and very often respectively on the basis of their occurrence during one month prior to the survey. ${ }^{23}$ Among the stress instruments that measure the degree to which life events are perceived as stressful, the Perceived Stress Scale (PSS) is widely used. The PSS has an internal consistency of 0.85 (Cronbach $\alpha$ co-efficient) and test retest reliability during a short retest interval (several days) of $0.85 .^{23}$ It assesses the degree to which participants evaluate their lives as being stressful during past month. It does not tie appraisal to a particular situation; the scale is sensitive to the non-occurrence of events as well as on going life circumstances. PSS-10 
scores are obtained by reversing the scores on the four positively stated items, e.g. $0=4,1=3,2=2,3=1$ and $4=0$ and then sum across all 10 items. Items $4,5,7$ and 8 are the positively stated items. Higher score indicate higher level of stress and lower score indicate lower level of stress. The PSS-10 has a possible range of scores from 0 to 40. The range of PSS scores were also divided in to stratified quartiles. The upper two and lower quartiles were combined ( 20 being the operational cut off value for the upper bound) and were labelled as stressed and not stressed respectively. This cut off value was selected in a way as selected by study from Egypt and Pakistan. ${ }^{16,24}$

Stressors - The potential stressors included in the questionnaire were derived by reviewing the literature and by conducting base line study on 50 students (10 students from each batch) on preliminary questionnaire which contain open ended question regarding stressors. The questionnaire was then modified accordingly in its final form with 29 stressors. For each potential stressor, the frequency of occurrence was classified as never, rarely, sometimes, often and always and scored as 1, 2, 3, 4 and 5 respectively. The severity of each stressor was rated using a Likert scale (1-10) ranging from not severe to very severe. The students were asked to indicate frequency and severity of stressors if any of the stressors had been affecting them.

\section{Data analysis}

The data was analysed using statistical package for social sciences (SPSS). The mean score of perceived stress were calculated. The number and percentage of stressed cases were calculated. The frequency was grouped according to the occurrence of stressors as never/rarely, sometime, and often/always. Percentage frequency of occurrence was calculated for each of the stressors from academic, psychosocial and health domains. Binary logistic regression analysis was carried out to access the stressors significantly influencing the stress. We considered perceived stress (stressed cases) as dependent variable and stressors as independent variables. $\beta$ coefficient, adjusted Odds ratio (OR), 95\% confidence interval (95\% $\mathrm{CI})$ were calculated. A p value of $<0.05$ was considered as significant.

\section{RESULTS}

Out of 500 students in five batches 452 students attended the study (95 of 2010, 92 of 2011, 92 of 2012, 87 of 2013 and 86 of 2014 batch respectively). The mean age was20.9 $(\mathrm{SD}=2.04)$ with a range of $17-32$ years. 243 students were male (53.8\%) and 209 (46.2\%) were female. $89.8 \%$ students had English medium schooling background. $36.9 \%$ students had family background of medical profession.

Table 1: Medical student's responses to the perceived stress scale.

\begin{tabular}{|c|c|c|c|c|c|}
\hline Statement & Never & Almost never & Sometimes & Often & $\begin{array}{l}\text { Very } \\
\text { often }\end{array}$ \\
\hline $\begin{array}{l}\text { In the last month, how often have you been upset because of } \\
\text { something that happened unexpectedly? }\end{array}$ & $37(8.2)$ & $40(8.8)$ & $234(51.8)$ & $64(14.2)$ & 77 (17.0) \\
\hline $\begin{array}{l}\text { In the last month, how often have you felt that you were } \\
\text { unable to control the important things in your life? }\end{array}$ & $55(12.2)$ & $65(14.4)$ & $172(38.1)$ & $87(19.2)$ & $73(16.2)$ \\
\hline $\begin{array}{l}\text { In the last month, how often have you felt nervous nervous } \\
\text { and stressed? }\end{array}$ & $26(5.8)$ & $44(9.7)$ & $185(40.9)$ & $88(19.5)$ & $109(24.1)$ \\
\hline $\begin{array}{l}\text { In the last month, how often have you felt confident about } \\
\text { your ability to handle your personal problems? }\end{array}$ & $104(23.0)$ & $148(32.7)$ & $155(34.3)$ & $30(6.6)$ & $15(3.3)$ \\
\hline $\begin{array}{l}\text { In the last month, how often have you felt that things were } \\
\text { going your way? }\end{array}$ & $57(12.6)$ & $85(18.8)$ & $176(38.9)$ & $76(16.8)$ & $58(12.8)$ \\
\hline $\begin{array}{l}\text { In the last month, how often have you found that you could } \\
\text { not cope with all the things that you had to do? }\end{array}$ & $42(9.3)$ & $64(14.2)$ & $240(53.1)$ & $69(15.3)$ & $37(8.2)$ \\
\hline $\begin{array}{l}\text { In the last month, how often have you been able to control } \\
\text { irritation in your life? }\end{array}$ & $82(18.1)$ & $126(27.9)$ & $167(36.9)$ & $48(10.6)$ & $29(6.4)$ \\
\hline $\begin{array}{l}\text { In the last month, how often have you felt that you were on } \\
\text { the top of things? }\end{array}$ & $36(8.0)$ & $52(11.5)$ & $186(41.2)$ & $97(21.5)$ & $81(17.9)$ \\
\hline $\begin{array}{l}\text { In the last month, how often have you been angered because } \\
\text { of things that were outside your control? }\end{array}$ & $36(8.0)$ & $65(14.4)$ & $164(36.3)$ & $95(21.0)$ & $92(20.4)$ \\
\hline $\begin{array}{l}\text { In the last month, how often have you felt difficulties were } \\
\text { piling up so high that you could not overcome them? }\end{array}$ & $52(11.5)$ & $84(18.6)$ & $204(45.1)$ & $59(13.1)$ & $53(11.7)$ \\
\hline
\end{tabular}

\section{Perceived stress}

Table 1 shows the responses of students to Perceived Stress Score - 10 scales. Mean PSS score in the study population was $20.3(\mathrm{SD}=6.15)$ with median of 20 $(\mathrm{IQR}=16-24)$. Mean PSS score for female (209) was $21.41(\mathrm{SD}=5.89)$ while for male $(243)$ it was $19.34(\mathrm{SD}=$ 6.23). Students with total PSS score 20 and above were 
considered to be stressed and those below were nonstressed. Nearly half $217(48.0 \%)$ of the students were found to be stressed. Females were found to be significantly associated with stress as compare to male $(\times 2=6.65, \mathrm{df}=1, \mathrm{p}<0.05)$.

\section{Frequency and severity of stressors}

The most frequently occurring academic sources of stress reported by students as often/always were performance in examination $(40.3 \%)$ and frequency of examination (39.2\%). Psychosocial sources of stress reported as often/always were lack of entertainment in the institution (48.5\%) and high parental expectation $(36.3 \%)$ and most common health related stressor reported as often/always was quality of food in mess $(50.7 \%)$. Quality of food in mess, lack of entertainment in the institution, performance in examination, frequency of examination, class attendance, lack of time for recreation and high parental expectation were rated as most severe (Table 2).

Binary logistic regression analysis of academic, psychosocial and health related stressors influencing stress.

Table 2: Frequency and severity (rated in a likert scale of 1-10) of 29 stressors as reported by the students.

\begin{tabular}{|c|c|c|c|c|c|}
\hline \multirow{2}{*}{ Sources of stress } & \multicolumn{3}{|c|}{ Frequency of occurrence } & \multicolumn{2}{|c|}{ Severity } \\
\hline & Never/rarely & sometimes & Often/always & Median & IQR \\
\hline \multicolumn{6}{|l|}{ Academic stressors } \\
\hline Feeling of adoption of wrong carrier field & $154(34.1)$ & $205(45.4)$ & $93(20.6)$ & 4 & $1-7$ \\
\hline Frequency of examination & 48 (10.6) & $227(50.2)$ & $177(39.2)$ & 6 & $3-8$ \\
\hline Performance in examination & $45(10.0)$ & $225(49.8)$ & $182(40.3)$ & 6 & $4-8$ \\
\hline Academic curriculum & $123(27.2)$ & $227(50.2)$ & $102(22.6)$ & 4 & $1-6$ \\
\hline Class attendance & $134(29.6)$ & $151(33.4)$ & $167(36.9)$ & 5 & $1-8$ \\
\hline Quality of class lectures & $104(23.0)$ & $258(57.1)$ & $90(19.9)$ & 5 & $1-6$ \\
\hline Non availability of adequate learning material & $212(46.9)$ & $196(43.4)$ & $44(9.7)$ & 1 & $1-5$ \\
\hline Lack of time for recreation & 99 (21.9) & $197(43.6)$ & $156(34.5)$ & 5 & $1-8$ \\
\hline Competition with peer & $137(30.3)$ & $232(51.3)$ & $83(18.4)$ & 4 & $1-6$ \\
\hline Performance in practical & $65(14.4)$ & $253(56.0)$ & $134(29.6)$ & 5 & $2-7$ \\
\hline Need of special guidance from faculty & $150(33.2)$ & $230(50.9)$ & $72(15.9)$ & 4 & $1-6$ \\
\hline \multicolumn{6}{|l|}{ Psychosocial stressors } \\
\hline High parental expectation & $106(23.5)$ & $182(40.3)$ & $164(36.3)$ & 5 & $1-8$ \\
\hline Loneliness & $111(24.6)$ & $240(53.1)$ & $101(22.3)$ & 5 & $1-7$ \\
\hline Family problems & $218(48.2)$ & $191(42.3)$ & $43(9.5)$ & 1 & $1-5$ \\
\hline Accommodation away from home & $151(33.4)$ & $212(46.9)$ & 89 (19.7) & 3 & $1-6$ \\
\hline Reading text books & $194(42.9)$ & $214(47.3)$ & $44(9.7)$ & 2 & $1-5$ \\
\hline Lack of entertainment in the institution & $67(14.8)$ & $166(36.7)$ & $219(48.5)$ & 6 & $3-9$ \\
\hline Difficulty in the journey back to home & $184(40.7)$ & $193(42.7)$ & 75 (16.6) & 2 & $1-5$ \\
\hline Financial strain & $193(42.7)$ & $208(46.0)$ & $51(11.3)$ & 2 & $1-6$ \\
\hline Inability to socialize with peer & 185 (40.9) & $224(49.6)$ & $43(9.5)$ & 2 & $1-5$ \\
\hline Living conditions in the hostel & $85(18.8)$ & $248(54.9)$ & $119(26.3)$ & 5 & $2-7$ \\
\hline Member of fraternity or sorority & $202(44.7)$ & $204(45.1)$ & $46(10.2)$ & 2 & $1-5$ \\
\hline Adjustment with roommates & $245(54.2)$ & $139(30.8)$ & $68(15.0)$ & 1 & $1-5$ \\
\hline Difficulty in love relationship & $215(47.6)$ & $154(34.1)$ & $83(18.4)$ & 1 & $1-6$ \\
\hline \multicolumn{6}{|l|}{ Health related stressors } \\
\hline Sleeping disorder & $178(39.4)$ & $195(43.1)$ & $79(17.5)$ & 3 & $1-6$ \\
\hline Physical activity & $329(72.8)$ & $102(22.6)$ & $21(4.6)$ & 1 & $1-1$ \\
\hline Exercise & $165(36.5)$ & $219(48.5)$ & $68(15.0)$ & 3 & $1-6$ \\
\hline Alcohol/drug abuse/smoking & $353(78.1)$ & $71(15.7)$ & $28(6.2)$ & 1 & $1-1$ \\
\hline Quality of food in mess & $44(9.7)$ & $179(39.6)$ & $229(50.7)$ & 7 & $4-10$ \\
\hline
\end{tabular}

A binary logistic regression was performed to ascertain the effect of academic stressors on the likelihood that participants had stress. The logistic regression model was statistically significant, $x 2=33.44, \mathrm{p}<0.05$. The model correctly classified $61.9 \%$ cases. Feeling of adoption of wrong carrier field, frequency of examination and lack of time for recreation were found to be significantly associated $(\mathrm{p}<0.05)$ with perceived stress. Students who were feeling medical sciences as a wrong choice for carrier had 1.7 times ( $\mathrm{CI}=1.02$ - 2.78) more chances of developing stress as compare to students who choose it with their own will. Similarly high frequency of 
examination and lack of recreation active in college campus had high odds of developing stress among students i.e $1.6(\mathrm{CI}=1.04-2.4$ and 1.08-2.5 respectively) (Table 3). Class attendance, quality of class lectures and need of special guidance from faculty were found to be inversely associated with stress i.e students who were more worried about class attendance, good quality of class lectures and need of special guidance from faculty were less likely to be stressed.

Another binary logistic regression was performed to quantify the effect of psychosocial stressors. The logistic model was found to be statistically significant $\left(x_{2}=32.73\right.$, $\mathrm{p}<0.05)$. This model classified $59.5 \%$ correctly. Lack of entertainment in the institution was found to be significantly associated with stress $(p<0.05)$. Likelihood of developing stress was found to be almost double when students felts lack of entertainment tools in institution campus $(\mathrm{OR}=2.04, \mathrm{CI}=1.35-3.09)$. Inverse association of some psychosocial stressors (reading more books, living condition in hostel, member of fraternity or sorority and adjustment with roommates) were found with stress i.e. students who were more worried about reading text book, their groups and adjustment with roommates were less likely to be stressed (Table 4).

Table 3: Binary logistic regression analysis of academic stressors influencing stress.

\begin{tabular}{|llll|}
\hline Academic variables & $\boldsymbol{\beta}$ coefficient & P value & OR (95\% CI) \\
\hline Feeling od adoption of wrong carrier field & 0.526 & 0.040 & $1.7(1.02-2.78)$ \\
Frequency of examination & 0.459 & 0.032 & $1.6(1.04-2.40)$ \\
Performance in examination & 0.337 & 0.116 & $1.4(0.92-2.13)$ \\
Academic curriculum & 0.338 & 0.128 & $1.5(0.89-2.43)$ \\
Class attendance & -0.257 & 0.243 & $0.77(0.50-1.19)$ \\
Quality of class lectures & -0.213 & 0.425 & $0.81(0.48-1.37)$ \\
Non availability of adequate learning material & 0.080 & 0.818 & $1.08(0.55-2.13)$ \\
Lack of time for recreation & 0.497 & 0.020 & $1.6(1.08-2.5)$ \\
Competition with peer & 0.159 & 0.539 & $1.17(0.71-1.94)$ \\
Performance in practical & 0.159 & 0.539 & $1.17(0.71-1.94)$ \\
Need of special guidance from faculty & -0.010 & 0.971 & $0.99(0.57-1.73)$ \\
\hline
\end{tabular}

Table 4: Binary logistic regression analysis of psychosocial stressors influencing stress.

$\begin{array}{llll}\text { Psychosocial variables } & \beta \text { coefficient } & \text { P value } & \text { OR (95\% CI) } \\ \text { High parental expectation } & 0.280 & 0.208 & 1.3(0.86-2.04) \\ \text { Loneliness } & 0.505 & 0.050 & 1.7(1.0-2.75) \\ \text { Family problems } & 0.550 & 0.150 & 1.7(0.82-3.67) \\ \text { Accommodation away from home } & 0.206 & 0.438 & 1.2(0.73-2.07) \\ \text { Reading text books } & -0.213 & 0.551 & 0.81(0.40-1.62) \\ \text { Lack of entertainment in the institution } & 0.712 & 0.001 & 2.04(1.35-3.09) \\ \text { Difficulty in the journey back to home } & 0.113 & 0.692 & 1.1(0.64-1.95) \\ \text { Financial strain } & 0.005 & 0.989 & 1.01(0.049-2.03) \\ \text { Inability to socialize with peer } & 0.292 & 0.442 & 1.3(0.64-1.95) \\ \text { Living conditions in the hostel } & -0.482 & 0.054 & 0.62(0.38-1.01) \\ \text { Member of fraternity or sorority } & -0.564 & 0.105 & 0.57(0.29-1.13) \\ \text { Adjustment with roommates } & -0.094 & 0.754 & 0.91(0.50-1.64) \\ \text { Difficulty in love relationship } & 0.094 & 0.725 & 1.1(0.65-1.85)\end{array}$

Table 5: Binary logistic regression analysis of health related stressors influencing stress.

\begin{tabular}{|llll|}
\hline Health related variables & $\boldsymbol{\beta}$ coefficient & P value & OR (95\% CI) \\
\hline Sleeping disorder & 1.225 & $<0.001$ & $3.4(1.91-6.04)$ \\
Physical activity & -0.703 & 0.167 & $0.50(.18-1.34)$ \\
Exercise & -0.427 & 0.138 & $0.65(.37-1.15)$ \\
Alcohol/ drug abuse/smoking & -0.299 & 0.487 & $0.74(.32-1.72)$ \\
Quality of food in mess & 0.036 & 0.853 & $1.04(.71-1.52)$ \\
\hline
\end{tabular}

Binary logistic regression analysis was performed to quantify the effect of health related stressors. The logistic model was found to be statistically significant $\left(x_{2}=20.4\right.$, $\mathrm{p}<0.05)$. This model classified $59.3 \%$ correctly. Sleep 
disorder was found to be significantly associated with stress $(p<0.001)$. Respondents in whom frequency of sleep disorder was often/always were over 3 times more chances $(\mathrm{CI}=1.91-6.04)$ to develop stress in comparison to those in whom this stressor was less than often. Inverse association of some health related stressor (physical activity, exercise and Alcohol/ drug abuse/smoking) were found with stress (Table 5).

\section{DISCUSSION}

Medical education renders significant amount of stress to the students 25-30. Medical students are expected to learn and master a huge amount of knowledge, attitudes and skills for which they have to work hard which in turn put them under a lot of stress. Our study revealed that $48 \%$ of students are having stress which is comparable to other studies conducted at Surat $(41.2 \%)^{31}$, Iran $(44 \%)^{29}$ and Malaysia $(41.9 \%)^{19}$. Studies of medical students from Saudi Arabia, India and Thailand identified a high frequency of stress of $63 \%, 89.64 \%$ and $61.4 \%$ respectively. ${ }^{32-34}$ The mean PSS score in our study was 20.3 (21.4 for female and 19.3 for male) which was lower than then that of Shah et al study. ${ }^{16}$ It might be because we had used PSS 10 scale and they had used PSS 14 scale for scoring of stress. Like that of Shah et al study stress was found to be significantly more among female as compare to male in our study too. ${ }^{16}$ Medical students go through not only the stress imposed by medical education but also routine everyday life stressor which may explain the level of severe stress noted among medical students. In our study the most frequently occurring stressors were quality of food in mess $(50.7 \%)$, lack of entertainment in the institution $(48.5 \%)$, performance in examination $(40.3 \%)$, frequency of examination (39.2\%), class attendance $(36.9 \%)$, high parental expectation $(36.3 \%)$ and lack of time for recreation $(34.5 \%)$ and also the students rated these stressors as severe. This was in accordance with studies conducted by Shah et al and Sreerama reddy et al. ${ }^{16,35}$

In our study academic stressors- feeling of adoption of wrong carrier field, frequency of examination and lack of time for recreation were found to be significantly associated with stress. Previous studies have also reported that academic stressors to be the common sources of stress among medical students. ${ }^{17-20,30,35}$ Even though exams are the major source of stress, they are necessary in the medical training as a tool for evaluation and to encourage students learning. More objectivity in the examination and inclusion of exam oriented training in medical teaching might be helpful to reduce the stress. Among psychosocial factors lack of entertainment was found to be significantly associated with stress. Earlier studies have reported psychosocial factors to be important sources of stress for medical students. ${ }^{17,30,36}$ Among health related stressor sleep disorder was found to be significantly associated with stress in our study. There may be a need to reconstruct the teaching schedule that provide sufficient time and facilities in the campus for recreation and sports apart from proper academics. Although these facilities were available in our institution they were felt to be inadequate by the students. Regular mess inspections, proper reporting and corrective measures are regularly carried out by our institution. Despite these efforts frequency and severity of quality of food in mess was found to be very high, indicating the need of more attention by the institution to improve the quality of food in mess.

\section{CONCLUSION}

The Study concluded that students reported high level of stress. Both academic, psychosocial and health related factors are perceived cause of stress in students at Rohilkhand Medical College. As stress has detrimental effects both on the health as well as the academic performance of the students, the college administration should incorporate stress management plans as a cocurricular activity. The stressors at the campus should be identified, discussed with, and proper coping assistance should be provided to individual students. It also suggested need for measures to reduce such stress and future research.

\section{Funding: No funding sources}

Conflict of interest: None declared

Ethical approval: The study was approved by the Institutional Ethics Committee

\section{REFERENCES}

1. Md Aris SMY, Mariam AD. Differences in depression, anxiety and stress between low-and high-achieving students. J Sustain Sci Manage. 2011;6:169-78.

2. Khodarahimi S, Hashim IHM, Mohd-Zaharim N. Perceived stress, positive-negative emotions, personal values and perceived social support in Malaysian undergraduate students. Int J Psychol Behav Sci. 2012;2:1-8.

3. Habeeb KA. Prevalence of stressors among female medical students Taibah University. J Taibah Univ Med Sci. 2010;5:110-9.

4. Dahlin M, Joneborg N, Runeson B. Stress and depression among medical students: a cross sectional study. Med Educ. 2005;39:594-604.

5. Zocolillo M, Murphy GE, Wetzel RD. Depression among medical students. J Affect Disord. 1986;11:91-6.

6. Tyssen R, Vaglum P, Gronvold NT, Ekeberg O. Suicide ideation among medical students and youth physicians: a nationwide and prospective of prevalence and predictors. J Affect Disord. 2001;64:69-79.

7. Tyssen R, Hem E, Vaglum P, Gronvold NT, Ekeberg $\mathrm{O}$. The process of suicidal planning among medical doctors: predictors in a longitudinal Norwegian sample. J Affect Disord. 2004;80:191198. 
8. Sahraian A, Javadpour A. Sleep disruption and its correlation to psychological distress among medical students. SEMJ. 2010;11:12-7.

9. Zailinawati AH, Teng CL, Chung YC, Teow TL, Lee PN, Jamohni KS. Daytime sleepiness and sleep quality among Malaysian medical students. Med J Malaysia. 2009;64:108-10.

10. Tamaki T, Kaneita Y, Ohida T, Yokoyama E, Osaki $\mathrm{Y}$, Kanda $\mathrm{H}$, et al. Prevalence of and factors associated with smoking among Japanese medical students. J Epidemiol. 2010;20:339-45.

11. Chew-Graham CA, Rogers A, Yassin N. I wouldn't want it on my $\mathrm{CV}$ or their records: medical students experiences of help seeking for mental health problems. Med Educ. 2003;37:873-80.

12. Silver HK, Glicken AD. Medical student abuse. Incidence, severity, and significance. JAMA. 1990;263:527-32.

13. Niemi PM, Vainiomaki PT. Medical students' academic distress, coping and achievement strategies during the pre-clinical years. Teach Learn Med. 1999;11:125-34.

14. Paro HB, Morales NM, Silva $\mathrm{CH}$, Razende $\mathrm{CH}$, Pinto RM, Morales RR et al. Health related quality of life of medical students. Med Educ. 2010;44:22735.

15. Tyssen R, Vaghum P, Gronvold NT, Ekeberg O. Factors in medical school that predict postgraduate mental health problems in need of treatment: a nationwaide and longitudinal study. Med Educ. 2001;35:110-20.

16. Shah M, Hasan S, Malik S, Sreeramareddy CT. Perceived stress, sources and severity of stress among medical undergraduates in a pakistani medical school. BMC Medical Education. 2010;10:2.

17. Saipanish R. Stress among medical students in a Thai medical school. Med Teach. 2003;25:502-6.

18. Shah C, Trivedi R S. Common stressors and coping of stress. J Clin Diagn Res. 2009;(3):1621-16.

19. Sherina MS, Rampal L, Kaneson N. Psychological stress among undergraduate medical students. Med J Malaysia. 2004;59:207-11.

20. Shaikh BT, Kahloon A, Kazmi M, Khalid H, Nawaz K, Khan N, Khan S. Students, stress and coping strategies: a case of Pakistani medical school. Educ Health (Abingdon). 2004; 17:346-53.

21. Hatcher L, Prus JS. A measure of academic educational constraints: Out of- Class circumstances that inhibit college student development. Educational and Psychological measurement. 1991;51:953-63.

22. Hammer LG, Grigsby TL, Woods S. The conflicting demands of work, family and school among students of an urban university. The Journal of Psychology. 1998;132:220-7.

23. Cohen S, Kamarck T, Mermelstein R. A global measure of perceived stress. J Health Soc Behave. 1983;24:385-96.
24. Amr M, Gilany AH, El-Hawary A. Does gender predict students' stress in Mansoura, Egypt? Med Educ Online. 2008;13:12.

25. Dyrbye LN, Thomas MR, Eacker A, Harper W, Massie FS Jr, Power DV, et al. Race, ethnicity, and medical student well-being in the United States. Arch Intern Med. 2007;167:2103-9.

26. Mehanna Z, Richa S. Prevalence of anxiety and depressive disorders in medical students. Transversal study in medical students in the SaintJoseph University of Beirut. Encephale. 2006;32:976-82.

27. Saki M, Martinac M, Skobi H, Jakovljevi M.Depression among students of the Medical Faculty and doctors in Mostar. Med Arh. 2005;59:19-22.

28. Facundes VLD, Ludermir AB. Common mental disorders among health care students. Rev Bras Psiquiatr. 2005;27:194-200.

29. Assadi SM, Nakhaei MR, Najafi F, Fazel S. Mental health in three generations of Iranian medical students and doctors. A cross-sectional study. Soc Psychiatry Psychiatr Epidemiol. 2007;42:57-60.

30. Supe AN. A study of stress in medical students at Seth G.S. Medical College. J Postgrad Med. 1998; 44:1-6.

31. Solanki P, Desai B, Kavishwar A, Kantharia SL. Study of psychological stress among undergraduate medical students of Government Medical College, Surat. Int J Med Sci Public Health. 2012;1:38-42.

32. Abdulghani HM, AlKanhal AA, Mahmoud ES, Ponnamperuma GG, Alfaris EA. Stress and its effects on medical students: a cross-sectional study at a college of medicine in Saudi Arabia. J Health Popul Nutr. 2011;29:516-22.

33. Mannapur B, Dorle AS, Hiremath ID, Ghattargi CH, Ramadurg U, Kulkarni KR. A study of psycological stress in undergraduate medical students at S,N, Medical College, Bagalkot, Karnataka. J Clin Diagn Res. 2010;4:2869-74.

34. Abhay MB, Krishnakunar MK, Naranjan PC, Hiremath SG. Differences in perceived stress and its correlates among students in professional courses. J Clin Diagn Res. 2011;5:1228-33.

35. Sreeramareddy CT, Shankar PR, Binu VS, Mukhopadhyay C, Ray B, Menezes RG. Psychological morbidity, sources of stress and coping strategies among undergraduate medical students of Nepal. BMC Medical Education. 2007;7:26

36. Moffat KJ, McConnachie A, Ross S, Morrison JM. First year medical student stress and coping in a problem-based learning medical curriculum. Med Educ. 2004;38:482-91.

Cite this article as: Chaudhary V, Upadhyay D, Singh SP, Singh A, Joshi HS, Katyal R. A Cross sectional study to assess perceived stress and stressors associated with it among undergraduate medical students in a private medical college of Uttar Pradesh, India. Int J Community Med Public Health 2016;3:1752-8. 